Paper:

\title{
Statistical Analysis of Building Damage from the 2013 Super Typhoon Haiyan and its Storm Surge in the Philippines
}

\author{
Tanaporn Chaivutitorn*1, Thawalrat Tanasakcharoen ${ }^{* 2}$, Natt Leelawat ${ }^{* 2, * 3, \dagger}$, \\ Jing Tang ${ }^{* 3 * 4}$, Carl Vincent C. Caro ${ }^{* 5}$, Alfredo Mahar Francisco A. Lagmay ${ }^{* 6}$, \\ Anawat Suppasri ${ }^{* 7}$, Jeremy D. Bricker ${ }^{* 8}$, Volker Roeber ${ }^{* 9}$, \\ Carine J. Yi ${ }^{* 10}$, and Fumihiko Imamura*7 \\ ${ }^{* 1}$ School of Management, National Taiwan University of Science and Technology \\ 43, Sec. 4, Keelung Road, Taipei 106, Taiwan \\ ${ }^{* 2}$ Department of Industrial Engineering, Faculty of Engineering, Chulalongkorn University, Bangkok, Thailand \\ ${ }^{\dagger}$ Corresponding author, E-mail: natt.1@chula.ac.th,n.leelawat@gmail.com \\ ${ }^{* 3}$ Disaster and Risk Management Information Systems Research Group, Chulalongkorn University, Bangkok, Thailand \\ ${ }^{* 4}$ International School of Engineering, Faculty of Engineering, Chulalongkorn University, Bangkok, Thailand \\ ${ }^{*}$ Viosimos Integrated Planning Consultants Inc., Bagumbong Caloocan City, The Philippines \\ ${ }^{* 6}$ University of the Philippines Diliman, Manila, The Philippines \\ ${ }^{* 7}$ International Research Institute of Disaster Science (IRIDeS), Tohoku University, Miyagi, Japan \\ ${ }^{* 8}$ Department of Hydraulic Engineering, Delft University of Technology, Delft, The Netherlands \\ ${ }^{* 9}$ Université de Pau et des Pays de l'Adour, Anglet, France \\ ${ }^{* 10}$ R. Park \& Associates Inc., Ontario, Canada \\ [Received May 18, 2020; accepted July 14, 2020]
}

\begin{abstract}
In November 2013, Super Typhoon Haiyan (Yolanda) hit the Philippines. It caused heavy loss of lives and extensive damages to buildings and infrastructure. When collapsed buildings are focused on, it is interesting to find that these buildings did not collapse for the same reasons after the landfall of the typhoon and storm surge. The objective of this study is to develop a statistical model for building damage due to Super Typhoon Haiyan and its storm surge. The data were collected in collaboration with Tanauan Municipality, the Philippines. The data for the inundation map were obtained by field surveys conducted on-site to determine the cause of the damages inferred from satellite data. The maximum wind speed was derived from the Holland parametric hurricane model based on the Japan Meteorological Agency (JMA) typhoon track data and the inundation depth of storm surge was calculated using the MIKE model. Multinomial logistic regression was used to develop a model to identify the significant factors influencing the damage to buildings. The result of this work is expected to be used to prepare urban plans for preventing damage from future storms.
\end{abstract}

Keywords: building damage, statistical analysis, storm surge, Super Typhoon Haiyan

\section{Introduction}

The Philippines is the most storm-exposed country on earth [1]. The average number of tropical storms in the
Philippines that make landfall is 8 or 9 storms per year [1]. Super Typhoon Haiyan-local "Yolanda" was one of the strongest typhoons on record in the Philippines [2,3]. It formed in the low-pressure region in the West Pacific Ocean on November 2, 2013, and it was equivalent to a Category 5 on the Saffir-Simpson hurricane scale assessed by the Joint Typhoon Warning Center (JTWC) [4]. On November 8, 2013, Super Typhoon Haiyan hit the eastern part of the Philippines consisting of Tacloban, Palo, and Tanauan $[5,6]$.

Moreover, its wind blew seawater onto the shore. A storm surge was generated due to Super Typhoon Haiyan's strong winds. Tacloban City had the highest storm surge, about 6 meters tall. In total, 220,000 people became homeless [7]. More than 16 million people were affected, and 6,300 people died [8]. Around 1.14 million buildings were damaged [8]. In addition, the total financial loss of infrastructure, fisheries, and agriculture was valued at more than 39.8 billion PHP, approximately 0.77 billion USD [8]. The super typhoon and storm surge caused massive impacts to both lives and property. Consequently, many researchers have studied this typhoon and storm surge in order to reduce future storms' impacts.

The purpose of this research is to develop a statistical model for predicting damage levels of buildings due to a super typhoon and its storm surge. This study focuses on Super Typhoon Haiyan and its storm surge event in November 2013 in the Philippines. The study areas include Tacloban, Palo, Basey, Dulag, Marabut, Tanauan, and Tolosa.

Accordingly, understanding the factors that have a significant effect on collapsed buildings has many advan- 
tages. For instance, the proposed model is expected to assess the risk of building in each zone. There will then be ways to prepare buildings during super typhoons and storm surges. Moreover, the model can indicate whether the major damage to buildings occurred from wind or a storm surge. This work is expected to be used to develop urban planning for preventing damage in buildings located in typhoon and storm surgeprone areas.

\section{Background}

\subsection{Wind vs. Storm Surge Damage}

Many researchers have studied the differences between wind and water damage. Baradaranshoraka et al. [9] applied a statistical analysis to estimate the loss model from a hurricane in Florida, US, together with engineering judgment and hazard information (e.g., intensity and timing). The interaction of wind, storm surge, flood, and waves with low-rise structures was studied by Amoroso and Gurley [10]. They conducted a field study and found that wind-only damage is generally characterized as topdown while storm surge, flood, and wave damages are characterized as bottom-up [10]. Li et al. [11] used the non-stationary Poisson process to develop a probabilistic framework for hurricane damage assessment. They found that changes in wind speed and occurrence rate have significant impacts on hurricane damage [11]. They also found that hurricane wind speeds did not affect the expected hurricane damage [11].

\subsection{Building Damage Studies Using Statistical Analysis}

Ham et al. [12] developed a typhoon fragility measure for industrial buildings in Korea. They used the Monte Carlo simulation and compared the damage prediction with the post-disaster survey. Pita et al. [13] developed a novel approach to estimate the interior building damage caused by hurricanes using the study area of Florida based on a simulation of the co-occurrence of wind, rain, and damage. Statistical analysis was applied to the typhoon landing and failure mechanism of coastal low-rise buildings in China [14]. Their findings showed that most damaged houses were restricted to the exterior of the building and the roof was more likely to be damaged than the wall [14]. Another statistical analysis was conducted by Padgett et al. [15]. They identified significant parameters including surge elevation, number of spans, and relative surge [15]. By using the stepwise process and Monte Carlo simulation, Pinelli et al. [16] developed a probabilistic model to estimate the expected annual damage induced by hurricane winds in residential structures. They found that a sudden roof collapse results in immediate damage to the walls [16].

This study also reviewed other related research. Nishijima et al. [17] studied the preliminary impact assessment of typhoons using AGCM simulation and a probabilistic typhoon model and predicted the expected

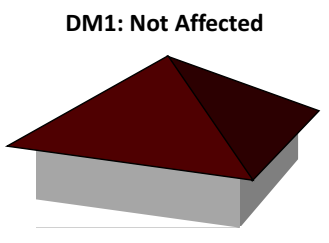

DM3: Highly Affected

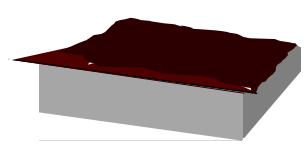

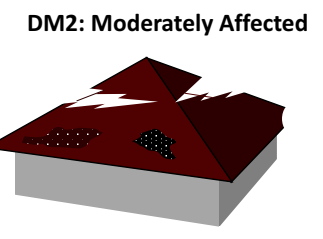

DM4: Totally Affected

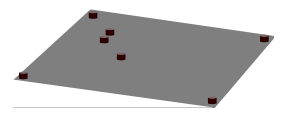

Fig. 1. Damage levels.

decreasing number of damaged residential buildings in Japan. A review of Duy et al. [18] found that the technical solutions recommended for existing and new buildings in cyclonic areas in Vietnam include planning, architectural, and structural solutions such as avoiding building long, thin houses.

Moreover, statistical analyses on building damage from natural disasters have been studied by many researchers $[19,20]$. Ordinal logistic regression was used to assess the building damage from the 2011 tsunami disaster in Japan [21]. Multinomial logistic regression was used to analyze the building damage from the 2011 tsunami in Japan [22,23] and the 2004 Indian Ocean tsunami in Sri Lanka [24]. In addition, linear and non-linear logistic regression approaches were used to estimate the fatality ratios from the 2011 tsunami in Japan $[25,26]$.

\section{Research Design and Methodology}

\subsection{Dependent Variable}

In this study, the dependent variable is the damage levels of buildings, which can be categorized into four levels that are defined by the Japan International Cooperation Agency (JICA): "DM1" Not Affected, "DM2" Moderately Affected (roof is damaged), "DM3" Highly Affected (roof is gone/"no roof"), and "DM4" Totally Affected. The damage levels are illustrated in Fig. 1.

\subsection{Independent Variable}

The potential independent variables assumed to be used in this study were chosen based on previous studies: wind speed and inundation depth of storm surge $[15,16]$. When the super typhoon occurs, a storm surge will be induced. The depth of the storm surge inundation was obtained using two models: DHI-MIKE21 and Delft3D, which are hydraulic models. These models have been evaluated as high quality and technically sound [27]. Therefore, these two models were chosen to compute the depth of the storm surge inundation.

In addition, due to the diversity in the affected areas, a location characteristic was expected to be a criterion 
for categorizing. As a result, it was planned that the data would be grouped based on location characteristics before data analysis.

\subsection{Assumption}

Since people in the same location quite often have a similar lifestyle, residences are built in the same way (e.g., number of floors). Thus, the assumption is that buildings in the same general location have the same characteristics.

\subsection{Research Design}

\subsubsection{Descriptive Statistics}

Each independent variable was analyzed using Minitab 17 in order to observe the descriptive profile.

\subsubsection{Correlated Predictor Testing}

It was confirmed that all independent variables were independent; in other words, they are not correlated according to Pearson Momentum Correlation Analysis in IBM SPSS Statistics 22. It is necessary to check this assumption before performing regression analysis because of the possibility of multi-collinearity, which occurs when there is a high level of correlation between independent variables. It affects the coefficient estimations of the regression model.

\subsubsection{Statistical Methods}

Linear regression analysis is simpler than other regression techniques. However, it has many important assumptions: The variables should have normal distributions and the variance of errors should be constant. Moreover, the mean of errors should be equal to zero and be independent [26]. The fundamental descriptive data analysis found that this assumption was violated as the variables do not have a normal distribution. Therefore, linear regression analysis was not applied.

In fact, in addition to the normal distribution assumption being violated, the dependent variable is categorical. Thus, logistic regression is considered suitable. There are three types of logistic regression: (1) binary logistic regression, (2) ordinal logistic regression, (3) multinomial logistic regression.

From the above, the data were analyzed using IBM SPSS Statistics 22. Multinomial logistic regression is suitable for analyzing the data in this study because the dependent variable can be categorized which has more than two categories. Moreover, ordinal logistic regression is expected to be suitable since the dependent variable is likely to have a natural order.

\subsubsection{Statistical Model Development}

The data were analyzed to develop a statistical model using the dependent variable: damage levels of buildings (DM) and independent variables: wind speed and storm surge inundation depth. However, the nature of the building damage from the storm differs from that of the storm surge. Therefore, the separately developed statistical models are expected to be suitable.

As a result, in each location, three models were developed: (1) damage models using the "entire" dataset; (2) damage models using the datasets "without" storm surge inundation (i.e., the data whose storm surge = 0.000 ; these were buildings damaged by storm winds alone); and (3) damage models using the datasets "with" storm surge inundation (i.e., the data whose storm surge $\neq 0.000$; these were the buildings damaged by both storm winds and the storm surge).

\subsubsection{Accuracy Testing}

The data were separated into training $(80 \%)$ and testing $(20 \%)$ datasets. The models were checked for their accuracy by fitting them with another dataset that was collected and kept separately for checking the accuracy of each model.

\subsection{Data Collection}

The field survey was conducted in 2013-2014 to collect detailed data immediately after the disaster. However, the data collected via field survey were not adequate. Therefore, in this study decided to combine satellite data and other sources [27]. The parameters were collected and computed: (1) maximum wind speed, derived from the Holland parametric hurricane model based on the Japan Meteorological Agency (JMA) typhoon track data; and (2) storm surge inundation depth, Delft3D models run with $25 \mathrm{~m}$ resolution over high-resolution topographic data and MIKE21 models run with $100 \mathrm{~m}$ resolution over high-resolution topographic data. The setup of the parametric hurricane and hydrodynamic/wave models was the same as described in Bricker et al. [30] and Watanabe et al. [31].

\subsection{Data Analysis and Results}

During data preprocessing from all collected data, the data using the MIKE21 model to generate the depth of storm surge inundation was selected to develop statistical models because the data using the MIKE21 model was more complete. There were originally 86,890 pieces of data; once the missing data were cleaned, 66,651 piece were left. The remaining data were then separated into two sets with an equal proportion across all levels. The first dataset $(20 \%)$ was used for checking the accuracy of the model, while the second dataset $(80 \%)$ was used for developing the models. The second dataset was then divided into three locations due to the fact that seven locations are not on the same island, which can lead to differences in topography. As shown in Fig. 2, Basey and Marabut are located on Samar Island while Tacloban, Palo, Tanauan, Tolosa, and Dulag are located on Leyte Island. Thus, Basey and Marabut were named "Location 1," Tacloban was named "Location 2" because Tacloban is an urban city while other locations are municipalities. Since Palo, Tanauan, Tolosa, and Dulag are located in remote 


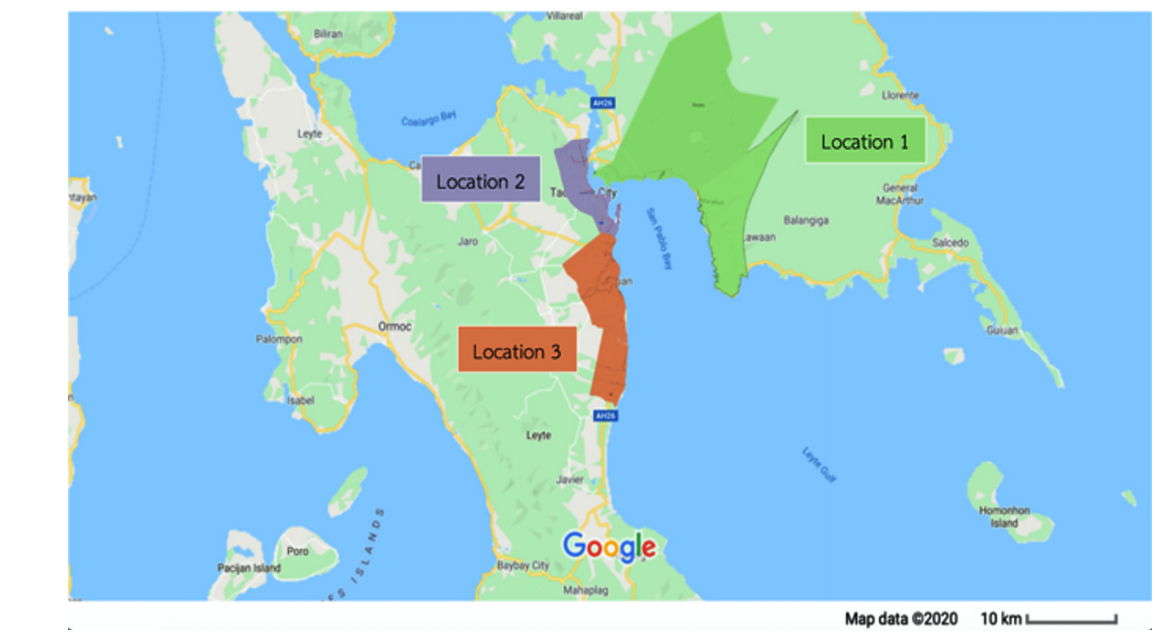

Note. Location 1: Basey and Marabut; Location 2: Tacloban; Location 3: Palo, Tanauan, Tolosa, and Dulag.

Fig. 2. Study area.

areas, they were called "Location 3." In addition, the difference in density of each location was used to differentiate these locations into three groups as well. The density of each location was approximately equal. Location 1 ranged from 93.09 to 123.9 people per $\mathrm{km}^{2}$ with an average of 108.5 people per $\mathrm{km}^{2}$. Location 2 has 2,284 people per $\mathrm{km}^{2}$. Location 3 ranges from 605.3 to 928.2 people per $\mathrm{km}^{2}$ and the average is 804.4 people per $\mathrm{km}^{2}$. Finally, Location 1 (Basey and Marabut) is $733 \mathrm{~km}^{2}\left(596 \mathrm{~km}^{2}\right.$ for Basey and $137 \mathrm{~km}^{2}$ for Marabut) [32]. Location 2 (Tacloban) is $106 \mathrm{~km}^{2}$ [33]. Location 3 is $248.8 \mathrm{~km}^{2}$ $\left(81 \mathrm{~km}^{2}\right.$ for Palo, $67.1 \mathrm{~km}^{2}$ for Tanauan, $22.6 \mathrm{~km}^{2}$ for Tolosa, and $78.1 \mathrm{~km}^{2}$ for Dulag) [33].

\subsubsection{Descriptive Statistics}

After grouping the data into the three locations, the data were preliminarily analyzed. Table 1 shows the descriptive statistics of the wind speed and storm surge inundation depth of Location 1, Location 2, and Location 3.

The minimum depth of storm surge inundation in every location is zero. This refers to the fact that not all buildings were inundated. The buildings with zero storm surge inundation depth suffered only from the power of the wind (storm). It is interesting to separate the dataset at each location further into two subsets: (1) those buildings with storm surge inundation, and (2) those without storm surge inundation.

\subsubsection{Correlation Analysis}

The data were tested for correlation using the Pearson Product-Moment Correlation coefficient to measure the strength of the relationship between the two independent variables [33], wind speed and the depth of the storm surge inundation.

The relationship between the two independent variables of Location 1, Location 2, and Location 3 for the damage model are $0.559,0.148$, and -0.088 , respectively. According to the rule of thumb for interpreting the size of a
Table 1. Descriptive statistics of wind speed and storm surge inundation depth.

\begin{tabular}{|c|c|c|c|c|}
\hline $\begin{array}{l}\text { Location- } \\
\text { Variable }\end{array}$ & $N$ & Min & Max & $\begin{array}{l}\text { Mean } \\
\text { (SD) }\end{array}$ \\
\hline \multicolumn{5}{|c|}{ Location 1 (Basey and Marabut) } \\
\hline $\begin{array}{l}\text { Wind speed } \\
{[\mathrm{m} / \mathrm{s}]}\end{array}$ & 1,051 & 76.913 & 83.435 & $\begin{array}{l}77.935 \\
(0.973)\end{array}$ \\
\hline $\begin{array}{l}\text { Storm surge } \\
\text { inundation } \\
\text { depth }[\mathrm{m}]\end{array}$ & 1,051 & 0.000 & 7.109 & $\begin{array}{r}1.0249 \\
(1.830)\end{array}$ \\
\hline \multicolumn{5}{|c|}{ Location 2 (Tacloban) } \\
\hline $\begin{array}{l}\text { Wind speed } \\
{[\mathrm{m} / \mathrm{s}]}\end{array}$ & 46,422 & 72.544 & 83.503 & $\begin{array}{l}82.409 \\
(1.563)\end{array}$ \\
\hline $\begin{array}{l}\text { Storm surge } \\
\text { inundation } \\
\text { depth }[\mathrm{m}]\end{array}$ & 46,422 & 0.000 & 5.731 & $\begin{array}{r}0.798 \\
(1.011)\end{array}$ \\
\hline \multicolumn{5}{|c|}{ Location 3 (Tanauan, Tolosa, and Dulag) } \\
\hline $\begin{array}{l}\text { Wind speed } \\
{[\mathrm{m} / \mathrm{s}]}\end{array}$ & 19,178 & 79.899 & 83.487 & $\begin{array}{l}82.040 \\
(0.994)\end{array}$ \\
\hline $\begin{array}{l}\text { Storm surge } \\
\text { inundation } \\
\text { depth }[\mathrm{m}]\end{array}$ & 19,178 & 0.000 & 9.196 & $\begin{array}{r}0.499 \\
(0.661)\end{array}$ \\
\hline
\end{tabular}

correlation coefficient, 0.7 to 0.9 is a high or strong correlation [34]. The results showed that there are no strong correlations between variables.

\subsubsection{Damage Models Using the "Entire" Dataset}

First, the data from each location were analyzed using ordinal regression, but the test of parallel lines (i.e., testing whether the coefficient estimates for each variable across categories are the same) was significant at $p<0.01$.

Therefore, the data of each location were analyzed using multinomial logistic regression. The results show that each location has a significant fit for the damage models $(p<0.01)$. 
Table 2 presents the results of multinomial logistic regressions for the three different locations (see Fig. 2). For each location, the model for each damage level $i$ follows Eq. (1), where $\mathrm{DM}_{i}$ is damage level $i, B_{\text {speed }, i}$ is a coefficient of wind speed, and $B_{\text {depth,i }}$ is a coefficient of storm surge inundation depth.

$$
\begin{aligned}
\ln \left[\frac{\operatorname{Pr}\left(\mathrm{DM}_{i}\right)}{\operatorname{Pr}\left(\mathrm{DM}_{\text {Base }}\right)}\right]= & B_{\text {speed }, i} \times \text { Speed } \\
& +B_{\text {depth }, i} \times \text { Depth }+c . .
\end{aligned}
$$

- Location 1. The results showed that there were nine pieces of DM1 data (1.1\% of all data), 540 pieces of DM2 data (64.3\%, the largest group), 0 pieces of DM3 data, and 291 pieces of DM4 data (34.6\%). Pseudo $R^{2}$ was computed. Three methods were used to estimate pseudo $R^{2}$ [35-37]. The results are as follows: $R_{\text {Cox and Snell }}^{2}$ is $0.096 ; R_{\text {Nagelkerke }}^{2}$ is 0.127 ; and $R_{\text {McFadden }}^{2}$ is 0.072 . On average, this model has a $67.5 \%$ prediction accuracy.

- Location 2. There were 6,636 pieces of DM1 data (17.9\%), 17,991 pieces of DM2 data (48.4\%), 113 pieces of DM3 data $(0.3 \%)$, and 12,398 pieces of DM4 data (33.4\%). $R_{\text {Cox and Snell }}^{2}$ is $0.072 ; R_{\text {Nagelkerke }}^{2}$ is 0.082 ; and $R_{M c F a d d e n}^{2}$ is 0.036 . On average, this model has a $54.1 \%$ correct prediction rate.

- Location 3. There were 164 pieces of DM1 data (1.1\%), 6,304 pieces of DM2 data (41.1\%), 241 pieces of DM3 data (1.6\%), and 8,634 pieces of DM4 data $(56.3 \%) . R_{\text {Cox and Snell }}^{2}$ is $0.035 ; R_{\text {Nagelkerke }}^{2}$ is 0.044 ; and $R_{\text {McFadden }}^{2}$ is 0.022 . On average, this model has a $60.4 \%$ correct prediction rate.

\subsubsection{Damage Models Using the Datasets "Without" Storm Surge Inundation}

Table 3 presents the results of multinomial logistic regression using only the data without storm surge inundation at each location.

- Location 1. There were two pieces of DM1 data $(0.3 \%), 458$ pieces of DM2 data $(69.1 \%)$, no pieces of DM3 data, and 203 pieces of DM4 data (30.6\%). $R_{\text {Cox and Snell is }}^{2} 0.158 ; R_{\text {Nagelkerke }}^{2}$ is 0.220 ; and $R_{\text {McFadden }}^{2}$ is 0.136 . On average, this model has a 76.3 correct prediction rate.

- Location 2. There were 3,048 pieces of DM1 data $(18.7 \%), 8,746$ pieces of DM2 data $(53.6 \%)$, 53 pieces of DM3 data $(0.3 \%)$, and 4,474 pieces of DM4 data $(27.4 \%)$. The model did not have a significant fit. As a result, all values of pseudo $R^{2}$ are 0.000 .

- Location 3. There were 131 pieces of DM1 data (1.9\%), 2,798 pieces of DM2 data (40.2\%), 74 pieces of DM3 data (1.1\%), and 3,961 pieces of DM4 data
Table 2. Coefficients of independent variables in damage model using entire data set.

\begin{tabular}{|l|l|c|c|c|}
\hline DM & Parameter & \multicolumn{3}{|c|}{ B } \\
\cline { 3 - 5 } & & Location 1 & Location 2 & Location 3 \\
\hline 2 & Intercept & $159.849^{* * *}$ & -0.334 & $82.055^{* * *}$ \\
\cline { 2 - 5 } & $\begin{array}{l}\text { Wind speed } \\
\text { [m/s] }\end{array}$ & $-1.990^{* * *}$ & $0.017^{* *}$ & $-0.952^{* * *}$ \\
\cline { 2 - 5 } & $\begin{array}{l}\text { Storm surge } \\
\text { inundation } \\
\text { depth [m] }\end{array}$ & -0.057 & $-0.112^{* * *}$ & $1.302^{* * *}$ \\
\hline 3 & Intercept & n/a & $-8.479^{*}$ & $81.133^{* * *}$ \\
\cline { 2 - 5 } & $\begin{array}{l}\text { Wind speed } \\
\text { [m/s] }\end{array}$ & n/a & 0.055 & $-0.985^{* * *}$ \\
\cline { 2 - 5 } & $\begin{array}{l}\text { Storm surge } \\
\text { inundation } \\
\text { depth [m] }\end{array}$ & $\mathrm{n} / \mathrm{a}$ & $-0.197^{*}$ & $1.900^{* * *}$ \\
\hline \multirow{2}{*}{4} & Intercept & $66.756^{* * *}$ & $2.821^{* * *}$ & $105.190^{* * *}$ \\
\cline { 2 - 5 } & $\begin{array}{l}\text { Wind speed } \\
\text { [m/s] }\end{array}$ & $-0.802^{* * *}$ & $-0.033^{* * *}$ & $-1.231^{* * *}$ \\
\cline { 2 - 5 } & $\begin{array}{l}\text { Storm surge } \\
\text { inundation } \\
\text { depth [m] }\end{array}$ & -0.035 & $0.471^{* * *}$ & $1.444^{* * *}$ \\
\hline \multirow{4}{*}{$*$ Significant at level $p<0.1(2-$ tailed $)$} & & \\
\hline
\end{tabular}

*Significant at level $p<0.1$ (2-tailed).

**Significant at level $p<0.05$ (2-tailed).

$* * *$ Significant at level $p<0.01$ (2-tailed).

Table 3. Coefficients of independent variables in damage model using datasets "without" storm surge inundation.

\begin{tabular}{|l|l|c|c|c|}
\hline DM & Parameter & \multicolumn{3}{|c|}{$B$} \\
\cline { 3 - 5 } & & Location 1 & Location 2 & Location 3 \\
\hline 2 & Intercept & $2,346.171^{* * *}$ & $2.617^{* * *}$ & $316.885^{* * *}$ \\
\cline { 2 - 5 } & $\begin{array}{l}\text { Wind } \\
\text { speed } \\
\end{array}$ & $-30.129^{* * *}$ & $-0.019^{*}$ & $-3.778^{* * *}$ \\
& {$[\mathrm{~m} / \mathrm{s}]$} & & & \\
\hline 3 & Intercept & n/a & 2.207 & $324.083^{* * *}$ \\
\cline { 2 - 5 } & $\begin{array}{l}\text { Wind } \\
\text { speed } \\
\end{array}$ & n/a & -0.077 & $-3.909^{* * *}$ \\
\hline \multirow{2}{*}{4} & In/s] & & & \\
\cline { 2 - 5 } & Intercept & $196.474^{* * *}$ & 0.728 & $362.910^{* * *}$ \\
\cline { 2 - 5 } & Wind & $-2.460^{* * *}$ & -0.004 & $-4.332^{* * *}$ \\
& speed & & & \\
& {$[\mathrm{m} / \mathrm{s}]$} & & & \\
\hline
\end{tabular}

*Significant at level $p<0.1$ (2-tailed).

**Significant at level $p<0.05$ (2-tailed).

$* * *$ Significant at level $p<0.01$ (2-tailed).

(56.9\%). $R_{\text {Cox and Snell }}^{2}$ is $0.088 ; R_{\text {Nagelkerke }}^{2}$ is 0.110 ; and $R_{\text {McFadden }}^{2}$ is 0.057 . On average, this model has a $61.2 \%$ correct prediction rate.

\subsubsection{Damage Models Using the Datasets "with" Storm Surge Inundation}

Table 4 presents the results of multinomial logistic regression using only the data with storm surge inundation at each location.

- Location 1. There were seven pieces of DM1 data $(4.0 \%), 82$ pieces of DM2 data $(46.3 \%)$, no DM3, 
Table 4. Coefficients of independent variables in damage models "with" storm surge inundation.

\begin{tabular}{|l|l|c|r|c|}
\hline DM & Parameter & \multicolumn{3}{|c|}{$B$} \\
\cline { 3 - 5 } & & Location 1 & Location 2 & Location 3 \\
\hline 2 & Intercept & $102.978^{* * *}$ & $-9.596^{* * *}$ & -2.490 \\
\cline { 2 - 5 } & $\begin{array}{l}\text { Wind speed } \\
\text { [m/s] }\end{array}$ & $-1.293^{* * *}$ & $0.131^{* * *}$ & 0.081 \\
\cline { 2 - 5 } & $\begin{array}{l}\text { Storm surge } \\
\text { inundation } \\
\text { depth [m] }\end{array}$ & 0.466 & $-0.175^{* * *}$ & $0.785^{*}$ \\
\hline 3 & Intercept & n/a & $-66.232^{* * *}$ & -8.536 \\
\cline { 2 - 5 } & $\begin{array}{l}\text { Wind speed } \\
\text { [m/s] }\end{array}$ & n/a & $0.758^{* * *}$ & 0.108 \\
\cline { 2 - 5 } & $\begin{array}{l}\text { Storm surge } \\
\text { inundation } \\
\text { depth [m] }\end{array}$ & n/a & $-0.454^{* *}$ & $1.588^{* * *}$ \\
\hline \multirow{3}{*}{4} & Intercept & $54.595^{* * *}$ & -1.074 & 5.939 \\
\cline { 2 - 5 } & $\begin{array}{l}\text { Wind speed } \\
\text { [m/s] }\end{array}$ & $-0.686^{* * *}$ & 0.006 & -0.023 \\
\cline { 2 - 5 } & $\begin{array}{l}\text { Storm surge } \\
\text { inundation } \\
\text { depth [m] }\end{array}$ & 0.692 & $0.786^{* * *}$ & $1.219^{* * *}$ \\
\hline
\end{tabular}

*Significant at level $p<0.1$ (2-tailed).

$* *$ Significant at level $p<0.05$ (2-tailed)

$* * *$ Significant at level $p<0.01$ (2-tailed).

and 88 pieces of DM4 data (49.7\%). $R_{\text {Cox and Snell }}^{2}$ is $0.140 ; R_{\text {Nagelkerke }}^{2}$ is 0.173 ; and $R_{\text {McFadden }}^{2}$ is 0.091 . On average, this model has a 53.7 correct prediction rate.

- Location 2. There were 3,588 pieces of DM1 data (17.2\%), 9,245 pieces of DM2 data (44.4\%), 60 pieces of DM3 data $(0.3 \%)$, and 7,924 pieces of DM4 data (38.1\%). $R_{\text {Cox and Snell }}^{2}$ is $0.138 ; R_{\text {Nagelkerke }}^{2}$ is 0.158 ; and $R_{M c F a d d e n}^{2}$ is 0.071 . On average, this model has a $56.2 \%$ correct prediction rate.

- Location 3. There were 33 pieces of DM1 data $(0.4 \%), 3,506$ pieces of DM2 data (41.8\%), 167 pieces of DM3 data (2.0\%), and 4,673 pieces of DM4 data $(55.8 \%) . R_{\text {Cox and Snell }}^{2}$ is $0.023 ; R_{\text {Nagelkerke }}^{2}$ is 0.029; and $R_{\text {McFadden }}^{2}$ is 0.015 . On average, this model has a $54.6 \%$ correct prediction rate.

\section{Discussion and Conclusions}

The result of correlation testing showed that there are no strong correlations between wind speed and the depth of the storm surge inundation variable. This means that there was no multicollinearity between the variables. Therefore, the regression model can be developed using only one or both variables. In this study, the regression models of each location were developed using multinomial logistic regression. Although the damage levels are likely to have a natural order, the results of parallel line testing show that they are not suitable for analysis using ordinal regression. Since the damage levels of buildings are determined by humans, they might not have an actual natural order.

\subsection{Models of Location 1}

The results show that the storm surge inundation depth did not have a significant effect at every damage level. Moreover, based on the damage models using the datasets "without" storm surge inundation show that wind speed significantly affected every damage level. Thus, only the wind speed variable affected the probability of the occurrence of different damage levels. Based on expert consultation, this seems to be because Basey and Marabut are located mainly in a mountainous area. Thus, the buildings may not have been damaged by the storm surge since the storm surge might not reach the buildings.

\subsection{Models of Location 2}

According to the damage models using the "entire" dataset, both wind speed and the storm surge inundation depth had a partial significant effect on damage levels. However, the wind speed variable at DM3 did not have a significant effect. The damage models using the datasets "with" storm surge inundation show that all variables had a partial significant effect on the damage levels. However, the wind speed variable did not have a significant effect at DM4. Since Tacloban is located in an urban area, there might be other potential factors that affect the probability of the occurrence of different damage levels. Based on expert consultation, in this case, it was hypothesized that debris floating along with the storm surge is another significant factor that causes damage to buildings.

\subsection{Models of Location 3}

According to the damage models using the "entire" dataset and the damage models using the datasets "without" storm surge inundation, the results show that all variables significantly affected the damage levels at every damage level. This means that both wind speed and the storm surge inundation depth variable affected the probability of the occurrence of different damage levels. Based on expert consultation, Tolosa, Tanauan, Palo, and Dulag are located in the plains area. Thus, buildings may be damaged from a storm surge since a storm surge can easily reach into buildings. However, the damage models using the datasets "with" storm surge inundation show that the wind speed variable did not have a significant effect at every damage level while the depth of the storm surge inundation had a significant effect at every damage level. This may be because the buildings that the storm surge can reach incur more major damage from the storm surge than storm winds.

\subsection{Conclusion}

The Philippines was the country most strongly affected by Super Typhoon Haiyan, with extreme losses of lives 
Table 5. Summary of findings.

\begin{tabular}{|l|l|l|}
\hline No. & $\begin{array}{c}\text { Location } \\
\text { characteristics }\end{array}$ & \multicolumn{1}{c|}{ Findings } \\
\hline 1 & Mountainous area & $\begin{array}{l}\text { Only typhoon wind speed significantly affected all damage levels. It is pos- } \\
\text { sible to use wind speed as the main parameter to predict damage levels. }\end{array}$ \\
\hline 2 & Urban plain area & $\begin{array}{l}\text { Wind speed significantly affected all damage levels. When looking at both } \\
\text { wind speed and storm surge, they partially affected the damage levels. Thus, } \\
\text { it is possible to use wind speed as the main parameter to predict damage } \\
\text { levels. It seems there are more parameters required for further investigating. }\end{array}$ \\
\hline 3 & Coastal plain area & $\begin{array}{l}\text { Wind speed significantly affected all damage levels. In addition, using both } \\
\text { wind speed and storm surge inundation depth also significantly affected dam- } \\
\text { age levels. Thus, it is possible to use only wind speed or use both wind and } \\
\text { storm surge inundation depth to predict damage levels. }\end{array}$ \\
\hline
\end{tabular}

and damage to buildings. When buildings are analyzed, it is interesting to note that all of the buildings did not collapse for the same reason after the impact of the typhoon and the storm surge. The purpose of this paper is to develop statistical models for building damage due to Super Typhoon Haiyan and its storm surge. In this work, following the assumption of the natural order, statistical analysis using ordinal regression was selected to identify the significant factors influencing the damage to buildings and develop statistical models. However, the results of parallel line testing showed that this situation is not suitable for using ordinal regression. Thus, statistical analysis using multinomial regression was selected instead. The models were conducted for three locations (seven cities) on the same island. This can lead to differences in topography, as shown in Table $\mathbf{5}$.

Results from Location 1 showed that only the storm wind speed variable was significant at every damage level. The results from Location 2 showed that the developed models do not fit because there might be additional factors because Tacloban is an urban city with unique characteristics. The results from Location 3 showed that both wind speed and the depth of storm surge inundation variables were significant at every damage level. These results showed that the wind speed variable was a significant factor in every location. According to other research, the wind speed parameter was always a significant factor in the models. However, Location 3 had another significant factor: the storm surge inundation depth. Therefore, risk reduction studies in the area of Location 3 should consider both wind speed and the depth of storm surge inundation. The different topography can lead to the different significant factors for predicting the damage of buildings.

This study is expected to help authorities in the area understand disaster risk and invest in disaster risk reduction for resilience according to the Sendai Framework for Disaster Risk Reduction 2015-2030 [38]. The results of this work are also expected to be used to develop urban planning for preventing damage to buildings located in a typhoon- and storm surge-prone area.

Although the models in this work were expected to be general models for risk analysis in other areas, the models were developed using the data in specific areas; there- fore, the models might not be generalized for use in other areas. Still, the developed models are hardly able to predict the probability of DM1 and DM3 occurrences since the data that were used to develop models were inadequate and the categorization of damage levels might not be suitable. Moreover, the factors influencing the damage to buildings for developing the models were limited. Nevertheless, developing an urban city's model for predicting the probability of damage level occurrence is necessary because there are many people living there.

Further studies might consider more potential parameters influencing the damage to buildings for developing statistical models such as debris floating with storm surge, construction of buildings, and the number of floors and age of buildings. In addition, big data from locations can be used to developing other models with a higher prediction accuracy.

\section{Acknowledgements}

This research is supported by the Radchadapisek Sompoch Endowment Fund (2020), Chulalongkorn University (763014 Climate Change and Disaster Management Cluster); JSPS Grant-in-Aid for Young Scientists (B) "Applying Developed Fragility Functions for the Global Tsunami Model (GTM)" (grant no. 16K16371); a JSPS-NRCT Bilateral Research Grant, the Core Research Cluster of Disaster Science in Tohoku University (Designated National University); Tokio Marine \& Nichido Fire Insurance Co., Ltd.; Willis Research Network (WRN; and EU Marie Curie project: GOLF (reference no. GOLF-777742). Volker Roeber acknowledges financial support from the Isite program Energy Environment Solutions (E2S), the Communauté d'Agglomération Pays Basque (CAPB) and the Communauté Région Nouvelle Aquitaine (CRNA) for the chair position HPC-Waves.

\section{References:}

[1] S. Brown, "The Philippines Is the Most Storm-Exposed Country on Earth," TIME, November 11, 2013, http://world.time.com/2013/11/ $11 /$ the-philippines-is-the-most-storm-exposed-country-on-earth [accessed September 16, 2017]

[2] H. Takagi, M. de Leon, M. Esteban, T. Mikami, and R. Nakamura, "Storm surge due to 2013 Typhoon Yolanda (Haiyan) in Leyte Gulf, the Philippines," M. Esteban, H. Takagi, and T. Shibayama (Eds.), "Handbook of Coastal Disaster Mitigation for Engineers and Planners," pp. 133-144, Elsevier, 2015.

[3] N. Leelawat, A. Suppasri, S. Kure, C. J. Yi, C. M. R. Mateo, and F. Imamura, "Disaster warning system in the Philippines through 
enterprise engineering perspective: A study on the 2013 Super Typhoon Haiyan," J. Disaster Res., Vol.10, No.6, pp. 1041-1050, doi: 10.20965/jdr.2015.p1041, 2015.

[4] H. S. Lee and K. O. Kim, "Storm surge and storm waves modelling due to Typhoon Haiyan in November 2013 with improved dynamic meteorological conditions," Procedia Engineering, Vol.116, pp. 699-706, 2015.

[5] A. M. F. Lagmay, R. P. Agaton, M. A. C. Bahala, J. B. L. T. Briones, K. M. C. Cabacaba, C. V. C. Caro, L. L. Dasallas, L. A. L. Gonzalo, C. N. Ladiero, J. P. Lapidez, M. T F. Mungcal, J. V. R. Puno, M. M A. C. Ramos, J. Santiago, J. K. Suarez, and J. P. Tablazon, "Devastating storm surges of Typhoon Haiyan,” Int. J. of Disaster Risk Reduction, Vol.11, pp. 1-12, 2015.

[6] A. Suppasri, C. J. Yi, N. Leelawat, M. Watanabe, J. D. Bricker, and F. Imamura, "Field Survey and Analysis of Damaged School Buildings by the 2013 Typhoon Haiyan and Storm Surge," J. of Japan Society of Civil Engineers, Ser. B2 (Coastal Engineering), Vol.71, No.2, pp. I_1669-I_1674, 2015.

[7] BBC News, "Mapping Typhoon Haiyan," http://www.bbc.com/ news/world-asia-24917722 [accessed September 16, 2017]

[8] Y. Tajima and T. Shimozono, "Super Typhoon Haiyan in the Philippines," Y. Hayashi, Y. Suzuki, S. Sato, and K. Tsukahara (Eds.) "Disaster Resilient Cities: Concepts and Practical Examples," pp. 21-29, Elsevier, 2016.

[9] M. Baradaranshoraka, J. P. Pinelli, K. Gurley, X. Peng, and M. Zhao, "Hurricane wind versus storm surge damage in the context of a risk prediction model," J. of Structural Engineering, Vol.143, No.9, 2017.

[10] S. D. Amoroso and K. R. Gurley, "Response of Structures to wind, storm surge, flood, and waves," D. B. Peraza, W. L. Coulbourne, and M. Griffith (Eds.), "Engineering Investigations of Hurricane Damage: Wind versus Water," pp. 62-79, American Society of Civil Engineers, 2014

[11] Q. Li, C. Wang, and H. Zhang, "A probabilistic framework for hurricane damage assessment considering non-stationarity and correlation in hurricane actions," Structural Safety, Vol.59, pp. 108-117, 2016.

[12] H. Ham, S. Lee, and H. Kim, "Development of typhoon fragility for industrial buildings," Proc. of the 7th Asia-Pacific Conf. on Wind Engineering, 2009.

[13] G. Pita, J. P. Pinelli, S. Cocke, K. Gurley, J. Mitrani-Reiser, J. Weekes, and S. Hamid, "Assessment of hurricane-induced internal damage to low-rise buildings in the Florida Public Hurricane Loss Model," J. of Wind Engineering and Industrial Aerodynamics, Vols.104-106, pp. 76-87, 2012

[14] Y. M. Dai, X. G. Yan, X. J. Wang, H. X. Sun, and Y. G. Li, "Statistics and Analysis of typhoons landing and failure mechanism of coastal low-rise buildings in China," Applied Mechanics and Materials, Vols.226-228, pp. 1072-1075, 2012.

[15] J. E. Padgett, A. Spiller, and C. Arnold, "Statistical analysis of coastal bridge vulnerability based on empirical evidence from Hurricane Katrina," Structure and Infrastructure Engineering, Vol.8, No.6, pp. 595-605, 2012.

[16] J. P. Pinelli, E. Simiu, K. Gurley, C. Subramanian, L. Zhang, A. Cope, J. J. Filliben, and S. Hamid, "Hurricane damage prediction model for residential structures," J. of Structural Engineering, Vol.130, No.11, pp. 1685-1691, 2004.

[17] K. Nishijima, T. Maruyama, and M. Graf, "A preliminary impact assessment of typhoon wind risk of residential buildings in Japan under future climate change," Hydrological Research Letters, Vol.6, pp. 23-28, 2012

[18] T. C. Duy, C. N. Xuan, M. N. Dai, H. N. Huu, and C. B. Tat, "Typhoons and technical solutions recommended for existing and new houses in the cyclonic regions in Vietnam," Electronic J. of Structural Engineering, Vol.8, Special Issue 2, pp. 8-18, 2008.

[19] A. Suppasri, I. Charvet, J. Macabuag, T. Rossetto, N. Leelawat, P. Latcharote, and F. Imamura, "Building damage assessment and implications for future tsunami fragility estimations," M. Esteban, H. Takagi, and T. Shibayama (Eds.), "Handbook of Coastal Disaster Mitigation for Engineers and Planners," pp. 147-178, Elsevier. 2015.

[20] A. Suppasri, P. Latcharote, J. D. Bricker, N. Leelawat, A. Hayashi, K. Tamashita, F. Makinoshima, V. Roeber, and F. Imamura, "Improvement of tsunami countermeasures based on lessons from the 2011 Great East Japan earthquake and tsunami - Situation after five years," Coastal Engineering J., Vol.58, No.4, 2016.

[21] N. Leelawat, A. Suppasri, I. Charvet, and F. Imamura, "Building damage from the 2011 Great East Japan tsunami: quantitative assessment of influential factors," Natural Hazards, Vol.73, No.2, pp. 449-471, 2014.

[22] N. Leelawat, A. Suppasri, I. Charvet, T. Kimura, D. Sugawara, and F. Imamura, "A study on influential factors on building damage in Kesennuma, Japan from the 2011 Great East Japan tsunami," Engineering J., Vol.19, No.3, pp. 105-116, 2015.
[23] W. Treeranurat, K. Saengtubtim, N. Wisittiwong, J. Tang, N. Leelawat, A. Suppasri, K. Pakaksung, and F. Imamura, "Building damage analysis from the 2011 Great East Japan tsunami," Proc. of the 2019 Int. Conf. on Engineering and Natural Science, pp. 33-39, 2019.

[24] N. Leelawat, A. Suppasri, O. Murao, and F. Imamura, "A study on the influential factors on building damage in Sri Lanka during the 2004 Indian Ocean tsunami," J. of Earthquake and Tsunami, Vol.10, No.2, Article No.1640001, 2016

[25] P. Latcharote, N. Leelawat, A. Suppasri, P. Thamarux, and F. Imamura, "Estimation of fatality ratios and investigation of influential factors in the 2011 Great East Japan tsunami," Int. J. of Disaster Risk Reduction, Vol.29, pp. 37-54, 2018.

[26] P. Latcharote, N. Leelawat, A. Suppasri, and F. Imamura, "Developing estimating equations of fatality ratio based on surveyed data of the 2011 Great East Japan tsunami," IOP Conf. Series: Earth and Environmental Science, Volume 56, IOP Publishing, 2017.

[27] National Weather Service, http://www.nws.noaa.gov/oh/rfcdev/ docs/Final_Report_EvaluationHydraulicModels.pdf [accessed October 16, 2017]

[28] G. A. F. Seber, "Linear Regression Analysis," Wiley, 1977.

[29] E. Mas, J. D. Bricker, S. Kure, B. Adriano, C. J. Yi, A. Suppasri, and S. Koshimura, "Field survey report and satellite image interpretation of the 2013 Super Typhoon Haiyan in the Philippines," Natural Hazards and Earth System Sciences, Vol.15, No.4, pp. 805-816, 2015.

[30] J. D. Bricker, H. Takagi, E. Mas, S. Kure, B. Adriano, C. J. Yi, and V. Roeber "Spatial variation of damage due to storm surge and waves during Typhoon Haiyan in the Philippines," J. of Japan Society of Civil Engineers, Ser. B2 (Coastal Engineering), Vol.70, No.2, pp. I_231-I_235, 2014.

[31] M. Watanabe, J. D. Bricker, K. Goto, and F. Imamura, "Factors responsible for the limited inland extent of sand deposits on Leyte Island during 2013 Typhoon Haiyan," J. of Geophysical Research: Oceans, Vol.122, No.4, pp. 2795-2812, 2017.

[32] "City Population," https://www.citypopulation.de/php/philippinesvisayas-admin.php [accessed March 16, 2018]

[33] "Pearson Product-Moment Correlation," https://statistics.laerd. com/statistical-guides/pearson-correlation-coefficient-statisticalguide.php [accessed March 16, 2018]

[34] D. E. Hinkle, W. Wiersma, and S. G. Jurs, "Applied Statistics for the Behavioral Sciences," 5th edition, Houghton Mifflin, 2003.

[35] D. R. Cox and E. J. Snell, "The Analysis of Binary Data," Chapman and Hall, 1989.

[36] N. J. Nagelkerke, "A note on a general definition of the coefficient of determination," Biometrika, Vol.78, No.3, pp. 691-692, 1991.

[37] D. McFadden, "Conditional logit analysis of qualitative choice behavior," Paul Zarembka (Ed.), "Frontiers in Econometric," pp. 105142, Wiley, 1974.

[38] "Sendai Framework for Disaster Risk Reduction 2015-2030," https://www.unisdr.org/files/43291_sendaiframeworkfordrren.pdf [accessed April 1, 2018]

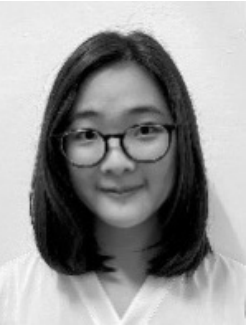

Name:

Tanaporn Chaivutitorn

Affiliation:

School of Management, National Taiwan University of Science and Technology

Address:

43 Sec. 4, Keelung Road, Taipei 106, Taiwan

Brief Career:

2018-2020 Research Assistant, Mahidol University 


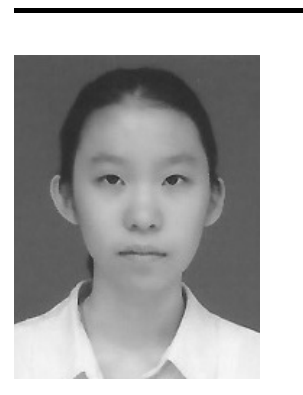

Name:

Thawalrat Tanasakcharoen

\section{Affiliation:}

Department of Industrial Engineering, Faculty of Engineering, Chulalongkorn University

Address:

48/370 Khokkrabue, Mueangsamutsakhon, Samutsakhon 74000, Thailand Brief Career:

2019 Joined Tang Tong Tai Part., Ltd.

$\begin{aligned} & \text { Name: } \\ & \text { Natt Leelawat }\end{aligned} \mid \begin{aligned} & \text { Affiliation: } \\ & \text { Assistant Professor, Department of Industrial } \\ & \text { Engineering, Faculty of Engineering, Chula- } \\ & \text { longkorn University } \\ & \text { Head, Disaster and Risk Management Informa- } \\ & \text { tion Systems Research Group, Chulalongkorn } \\ & \text { University } \\ & \text { Assistant Dean, Faculty of Engineering, Chula- } \\ & \text { longkorn University } \\ & \text { Director, Risk and Disaster Management Pro- } \\ & \text { gram, Graduate School, Chulalongkorn Univer- } \\ & \text { sity }\end{aligned}$

Address:

254 Phayathai Road, Pathumwan, Bangkok 10330, Thailand

Brief Career:

2007-2009 System Analyst, Bank of Thailand

2016-2017 Assistant Professor, Tohoku University

2017-2018 Lecturer, Chulalongkorn University

2018- Assistant Professor, Chulalongkorn University

Selected Publications:

- N. Leelawat, A. Suppasri, P. Latcharote, Y. Abe, K. Sugiyasu, and F.

Imamura, "Tsunami evacuation experiment using a mobile application: A design science approach," Int. J. of Disaster Risk Reduction, Vol.29, pp. 63-72, 2017.

- N. Leelawat, P. Latcharote, A. Suppasro, T. Sararit, M. Srivichai, J. Tang, T. Chua, D. Kumnetrut, K. Saengtabtim, and F. Imamura, "Today in Thailand: multidisciplinary perspectives on the current tsunami disaster risk reduction," Geological Society, London, Special Publications, Vol.501, 2020.

- N. Leelawat, A. Suppasri, I. Charvet, and F. Imamura, "Building damage from the 2011 Great East Japan tsunami: quantitative assessment of influential factors," Natural Hazards, Vol.73, No.2, pp. 449-471, 2014.

Academic Societies \& Scientific Organizations:

- Asia Oceania Geosciences Society (AOGS)

- Association for Information Systems (AIS)

- Institute of Electrical and Electronics Engineers (IEEE), Senior Member

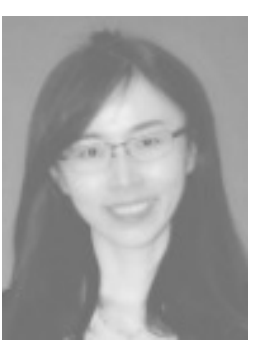

Name:

Jing Tang

\section{Affiliation:}

Lecturer, International School of Engineering, Faculty of Engineering, Chulalongkorn University

Address:

254 Phayathai Road, Pathumwan, Bangkok 10330, Thailand

Brief Career:

2013-2017 Enterprise System Transformation Consultant, based in Japan 2017-2019 Lecturer, Sirindhorn International Institute of Technology, Thammasat University

2019- Lecturer, Chulalongkorn University

\section{Selected Publications:}

- J. Tang, L. G. Pee, and J. Iijima, "Investigating the effect of business process orientation on organizational innovation performance," Information \& Management, Vol.50, No.8, pp. 650-660, 2013. - N. Leelawat, P. Latcharote, A. Suppasro, T. Sararit, M. Srivichai, J. Tang, T. Chua, D. Kumnetrut, K. Saengtabtim, and F. Imamura, "Today in Thailand: multidisciplinary perspectives on the current tsunami disaster risk reduction," Geological Society, London, Special Publications, Vol.501, 2020 .

- M. Fachrizal and J. Tang, "Forecasting annual solar PV capacity installation in Thailand residential sector: A user segmentation approach," Engineering J., Vol.23, No.6, pp. 99-115, 2019.

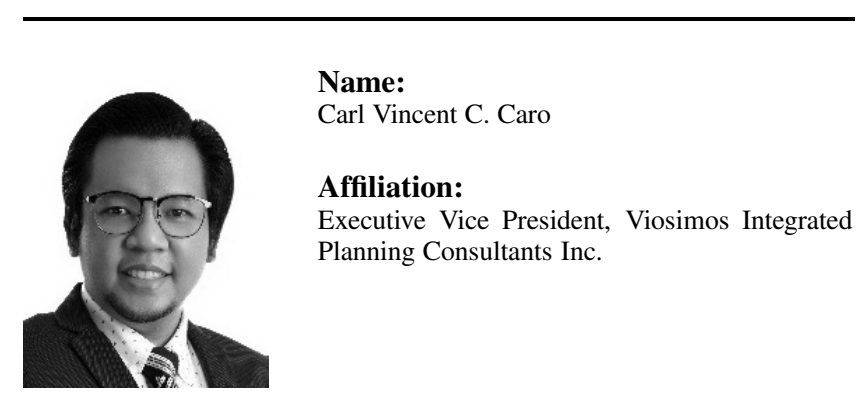

Address:

Block 5C Lot 2 Kingstown 1 Subdivision, Bagumbong Caloocan City 1421, The Philippines

\section{Brief Career:}

2013-2016 Department of Science and Technology, Nationwide

Operational Assessment of Hazards (NOAH)

2016-2020 Philippine Disaster Resilience Foundation

2020 Viosimos Integrated Planning Consultants Inc.

\section{Selected Publications:}

- "Devastating storm surges of Typhoon Haiyan," Int. J. of Disaster Risk

Reduction, Vol.11, pp. 1-12. 2015.

- "Probabilistic storm surge inundation maps for Metro Manila based on Philippine public storm warning signals," Natural Hazards and Earth System Science, Vol.15, pp. 557-570, 2015.

Academic Societies \& Scientific Organizations:

- Philippine Geographic Society

- American Geophysical Union (AGU)

- Asia Oceania Geosciences Society (AOGS) 


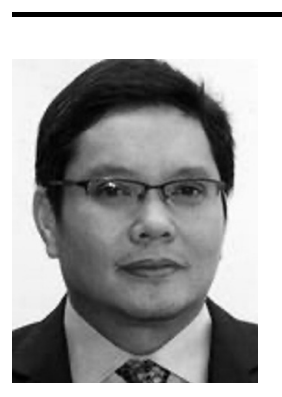

Name:

Alfredo Mahar Francisco A. Lagmay

\section{Affiliation:}

Executive Director, University of the Philippines (UP) Resilience Institute (RI)

Director, UP Nationwide Operational Assessment of Hazards (NOAH) Center

Professor, UP National Institute of Geological Sciences

\section{Address:}

\#6 Purok Aguinaldo, UP Campus, Diliman, Quezon City, Metropolitan

Manila 1101, The Philippines

\section{Brief Career:}

2013- Climate Science and Technology Adviser, Asian Network on Climate Science and Technology (ANCST), International Scientific Advisory Committee

\section{Selected Publications:}

- A. M. F. A Lagmay, C. Escape, A. A. Ybanez, J. J. Suarez, and G. Cuaresma, "Anatomy of the Naga City landslide and comparison with historical debris avalanches and analog models," Frontiers in Earth

Science, Vol.8, doi: 10.3389/feart.2020.00312, 2020.

- R. C. T. Gacusan and A. M. F A. Lagmay, "Shallow seismic reflection imaging of the Inabanga-Clarin portion of the North Bohol Fault, Central Visayas, Philippines," Geoscience Letters, Vol.6, No.1, Article No.9, 2019. - M. Lagmay and B. A. Racoma, "Lessons from tropical storms Urduja and Vinta disasters in the Philippines," Disaster Prevention and

Management, Vol.28, No.2, pp. 154-170, 2019.

- A. M. F. A. Lagmay, "An Open Data Law for Climate Resilience and Disaster Risk Reduction," Albert Del Rosario Institute for Strategic and International Studies, 2018.

Academic Societies \& Scientific Organizations:

- National Academy for Science and Technology (NAST), Academician

- Philippine Academic Society for Climate and Disaster Resilience, Co-Founder

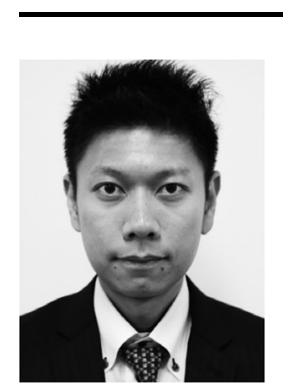

Name:

Anawat Suppasri

\section{Affiliation:}

Associate Professor, International Research Institute of Disaster Science (IRIDeS), Tohoku University

Address:

468-1 Aoba, Aramaki-Aza, Aoba, Sendai, Miyagi 980-8572, Japan Brief Career:

2010 Post-Doctoral Research Fellow, Disaster Control Research Center, Tohoku University

2012 Associate Professor, IRIDeS, Tohoku University

\section{Selected Publications:}

- A. Suppasri, K. Pakoksung, I. Charvet, C. T. Chua, N. Takahashi, T. Ornthammarath, P. Latcharote, N. Leelawat, and F. Imamura,

"Load-resistance analysis: An alternative approach to tsunami damage assessment applied to the 2011 Great East Japan tsunami," Natural Hazards and Earth System Sciences, Vol.19, pp. 1807-1822, 2019. - A. Suppasri, K. Fukui, K. Yamashita, N. Leelawat, H. Ohira, and F. Imamura, "Developing fragility functions for aquaculture rafts and eelgrass in the case of the 2011 Great East Japan tsunami," Natural Hazards and Earth System Sciences, Vol.18, pp. 145-155, 2018. - A. Suppasri, N. Leelawat, P. Latcharote, V. Roeber, K. Yamashita, A. Hayashi, H. Ohira, K. Fukui, A. Hisamatsu, D. Nguyen, and F. Imamura, "The 2016 Fukushima Earthquake and Tsunami: Preliminary research and new considerations for tsunami disaster risk reduction,” Int. J. of Disaster Risk Reduction, Vol.21, pp. 323-330, 2017.

Academic Societies \& Scientific Organizations:

- Japan Society of Civil Engineers (JSCE)

- Asia Oceania Geosciences Society (AOGS)

- European Geosciences Union (EGU)

\begin{tabular}{l} 
Name: \\
Aeremy D. Bricker \\
Associate Professor, Department of Hydraulic \\
Engineering, Delft University of Technology \\
Address: \\
Stevinweg 1, CN Delft 2628, The Netherlands \\
Brief Career: \\
2008 Senior Engineer, URS Corporation \\
2012 Visiting Associate Professor, Tokyo Institute of Technology \\
2013 Associate Professor, International Research Institute of Disaster \\
Science (IRIDeS), Tohoku University \\
2016 Associate Professor, Department of Hydraulic Engineering, Delft \\
University of Technology \\
Selected Publications: \\
- V. Roeber and J. D. Bricker, "Destructive tsunami-like wave generated \\
by surf beat over a coral reef during Typhoon Haiyan," Nature \\
Communications, Vol.6, No.1, pp. 1-9, 2015. \\
- J. D. Bricker and A. Nakayama, "Contribution of trapped air, deck \\
superelevation, and nearby structures to bridge deck failure during a \\
tsunami," J. of Hydraulic Engineering, Vol.140, No.5, Article \\
No.05014002, 2014. \\
Academic Societies \& Scientific Organizations: \\
- Japan Society of Civil Engineers (JSCE) \\
- International Association of Hydraulic Research (IAHR) \\
- American Society of Civil Engineers (ASCE7) Tsunami Loads and \\
Effects Subcommittee \\
\hline
\end{tabular}




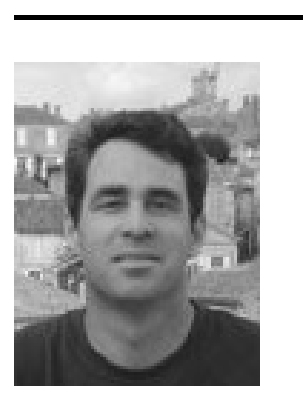

\section{Name:}

Volker Roeber

\section{Affiliation:}

Assistant Professor and Chair HPC-Waves, Université de Pau et des Pays de l'Adour

Address:

Avenue de l'Université, Pau 64000, France

Brief Career:

2013-2017 Senior Researcher, International Research Institute of Disaster Science, Tohoku University

2017- Affiliated Researcher/Affiliated Graduate Faculty, University of Hawaii at Manoa

2019- Assistant Professor, Chair HPC-Waves, Université de Pau et des

Pays de l'Adour

\section{Selected Publications:}

- C. Bosserelle, S. Williams, K. F. Cheung, T. Simi, T. Yamazaki, V. Roeber, T. Lay, E. M. Lane, R. Paulik, and L. Simanu, "Effects of rupture source and fringing reefs on the 2009 South Pacific tsunami inundation on southeast Upolu Island, Samoa," Earth and Space Science Open Archive, doi: 10.1002/essoar.10503515.1, 2020.

- C. H. Lashley, B. Zanuttigh, J. D. Bricker, J. van der Meer, C. Altomare, T. Suzuki, V. Roeber, and P. Oosterlo, "Benchmarking of numerical models for wave overtopping at dikes with shallow mildly sloping foreshores: Accuracy versus speed," Environmental Modelling and Software, Vol.130, Article No.104740. 2020.

- K. Minamidate, K. Goto, M. Watanabe, V. Roeber, K., Toguchi, M. Sannoh, Y. Nakashima, and H. Kan, "Millennial scale maximum intensities of typhoon and storm wave in the northwestern Pacific Ocean inferred from storm deposited reef boulders," Scientific Reports, Vol.10, Article No.7218, 2020.

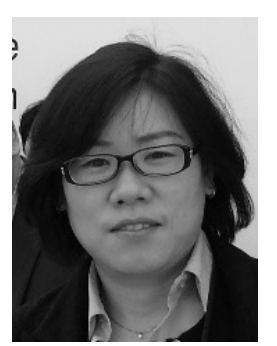

\section{Name:}

Carine J. Yi

\section{Affiliation:}

Senior Research Analyst, R. Park \& Associates Inc.

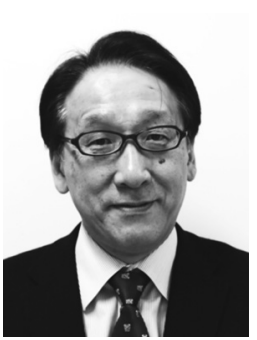

Name:

Fumihiko Imamura

\section{Affiliation:}

Professor and Director, International Research Institute of Disaster Science (IRIDeS), Tohoku University

\section{Address:}

468-1 Aoba, Aramaki-Aza, Aoba, Sendai, Miyagi 980-8572, Japan Brief Career:

1989-1990 Research Associate, Tohoku University 1993-1995 Associate Professor, School of Civil Engineering, Asian Institute of Technology

1995-2000 Associate Professor, Disaster Control Research Center, Tohoku University

1998-2000 Affiliated Faculty, Disaster Prevention Research Institute (DPRI), Kyoto University

2000-2012 Professor, Disaster Control Research Center, Tohoku University

2012-2013 Deputy Director, IRIDeS, Tohoku University

2014- Director, IRIDeS, Tohoku University

\section{Selected Publications:}

- S. Seto, F. Imamura, and A. Suppasri, "Challenge to Build the Science of Human Survival from Disaster Starting from Analysis for the 2011 Tohoku Tsunami,” J. Disaster Res., Vol.14, No.9, pp. 1323-1328, 2019.

- F. Imamura, S. P. Boret, A. Suppasri, and A. Muhari, "Recent occurrences of serious tsunami damage and the future challenges of tsunami disaster risk reduction," Progress in Disaster Science, Vol.1, 100009, 2019.

- F. Imamura, A. Suppasri, S. Sato, and K. Yamashita, "The Role of Tsunami Engineering in Building Resilient Communities and Issues to Be Improved After the GEJE," V. Santiago-Fandiño et al. (Eds.), "The 2011

Japan Earthquake and Tsunami: Reconstruction and Restoration - Insights and Assessment after 5 Years," pp. 435-448, Springer, 2017.

Academic Societies \& Scientific Organizations:

- Japan Society of Civil Engineers (JSCE)

- American Geophysical Union (AGU)

- Japan Society for Natural Disaster Science (JSNDS)

- Science Council of Japan, the Central Disaster Management Council in Japan, and the Study Group of the Reconstruction Design Council in Response to the Great East Japan Earthquake, Cabinet Office

\section{Address:}

1 Eva Road, Toronto, Ontario, Canada

Brief Career:

2001 Collision Data Technician, Institute for Traffic Accident Research and Data Analysis

2003 GIS Technician/CADD Technician, City of Mississauga

2007 Administration Director, Catirori Adventure \& Consulting

2013 Research Assistant, Centre for Regional Environmental Research,

Japanese National Institute for Environmental Studies (NIES)

2017 Assistant Professor, International Research Institute of Disaster

Science (IRIDeS), Tohoku University

\section{Selected Publications:}

- C. J. Yi and M. Kuri, "The prospect of online communication in the event of a disaster," J. of Risk Research, Vol.19, No.7, pp. 951-963, 2016.

- C. J. Yi, A. Suppasri, S. Kure, J. D. Bricker, E. Mas, M. Quimpo, and M. Yasuda, "Storm Surge Mapping due to Typhoon Haiyan and its impacts in Tanauan, Philippines," Int. J. of Disaster Risk Reduction, Vol.13, pp. 207-214, 2015.

- C. J. Yi, "Prediction of 137 Cs-contaminated soil losses by erosion using USLE in the Abukuma River Basin, Japan," Proc. of the 15th Asia Simulation Conf. 2015 (AsiaSim 2015), CCIS 603, pp. 110-117, 2016.

Academic Societies \& Scientific Organizations:

- Egyptian Journal of Remote Sensing and Space Sciences, Editorial

Manager (EM) 